\title{
AVALIAÇÃO DA ARBORIZAÇÃO DE ACOMPANHAMENTO VIÁRIO NA REGIÃO CENTRAL DE MARINGÁ (PR)
}

\author{
Ricardo Massulo Albertin* \\ Frederico Fonseca Silva** \\ Fábio Henrique Soares Angeoletto ${ }^{* * *}$ \\ Juliane Vier Vieira**** \\ Bruno Luiz Domingos De Angelis ${ }^{* * * * *}$
}

RESUMO: A arborização de acompanhamento viário faz parte da infraestrutura urbana e deve ser planejada e gerida em conjunto com os demais componentes urbanos, como forma de garantir níveis satisfatórios de qualidade de vida para a população. Neste contexto, o presente trabalho teve por objetivo avaliar a arborização de acompanhamento viário na Zona de Comércio Central (ZCC) da cidade de Maringá, Paraná, Brasil. Para isso, realizou-se levantamento censo quali-quantitativo no qual se identificou as árvores por meio da metodologia usual taxonômica e consulta bibliográfica, e avaliou-se as características do local de plantio, sistema radicular, copa e poda. Os resultados indicaram a presença de 1.758 exemplares arbóreos de 57 espécies, com predominância de sibipirunas (36,6\%) tipuanas $(20,4 \%)$ e alecrim de Campinas (15,8\%). Em relação ao local de plantio, 33,2\% das árvores estão plantadas no meio do lote. A avaliação do sistema radicular demonstrou que 30,0\% das árvores provocam rachaduras nas calçadas. Verificou-se que $20,0 \%$ das copas estão interferindo de forma negativa nas edificações. Os dados referentes às podas demonstraram que 19,0\% são de árvores em que não há indícios de poda. Conclui-se que a riqueza de espécies vegetais na área de estudo é correntemente alta, porém mal distribuída. Nota-se que em zonas comerciais há uma maior ocorrência de impactos negativos das copas sobre as edificações.

PALAVRAS-CHAVE: Ecologia urbana; Planejamento urbano; Vegetação urbana.

\footnotetext{
"Doutor em Geografia (Análise Ambiental), pela Universidade Estadual de Maringá. Paraná, Brasil.

*** Doutor em Produção Vegetal pela Universidade Estadual de Maringá - UEM, Brasil.

**** Doutor em Ecologia pela Universidade Autônoma de Madri, Espanha, Brasil.

***** Mestranda de Engenharia Civil pela Universidade Estadual de Londrina - UEl e Mestranda de Engenharia Urbana pela Universidade Estadual de Maringá - UEM, Brasil.

****** Doutor em Geografia pela Universidade de São Paulo - USP, Pós-Doutorado em Geografia da Universidade Federal do Paraná - UFPR, Brasil.
} 


\section{EVALUATION OF TREES IN STREETS IN DOWNTOWN MARINGÁ}

ABSTRACT: Trees in the streets are a characteristic of city infrastructure and should be planned and administered together with other urban components so that the population's life quality could be maintained at satisfactory levels. Current study evaluates the trees on the streets in downtown Maringá PR Brazil. A quality-quantity census was undertaken in which the trees were identified by taxonomy and bibliography, coupled to the characteristics of plantation sites, root system, top coverage and trimming. Results indicate 1,758 tree samples from 57 species, predominantly sibipirunas (36.6\%), tipuanas (20.4\%) and alecrim (15.8\%). Further, 33.2\% of the trees were planted in plots. Root system was evaluated and revealed that $30.0 \%$ of trees broke the sidewalks. It was also verified that $20.0 \%$ of top covers negatively interfered with buildings. Data on pruning and trimming revealed that $19.0 \%$ failed to show any trace of pruning. Results show that the richness of vegetal species in the study area is high but badly distributed. There are more negative impacts of tree top covers on buildings in commercial zones.

KEY WORDS: Urban ecology; Urban planning; Urban vegetation.

\section{INTRODUCÃO}

As cidades estão sofrendo uma crise ambiental, que causa uma série de impactos ambientais negativos. A arborização oferece um meio para ajudar a enfrentar este desafio e melhorar a qualidade de vida nas urbes (SHAFER; MOELLER, 1979).

A arborização de acompanhamento viário faz parte da infraestrutura urbana e deve ser planejada e gerida em conjunto com os demais componentes urbanos, tais como: sistema viário, sistema de drenagem pluvial, sistema de abastecimento de água, sistema de esgoto sanitário e sistema de energia elétrica, assim como os elementos móveis (pedestres e veículos). Logo, os poderes públicos responsáveis pela infraestrutura urbana têm a obrigação de criar planos, projetos e estratégias para facilitar a expansão da cobertura vegetal nas cidades (JIM, 2000).

Os benefícios da arborização viária são variáveis e de longo alcance, incluindo a melhoria estética das residências e das cidades, opção de babitat da fauna, sequestro e remoção de poluentes atmosféricos, redução do consumo 
de energia elétrica, minimização de poluição sonora (desempenho acústico), sombreamento, melhoria microclimática (aumento da umidade relativa do ar), deflatora do vento, aumento da área permeável e recarga de lençol freático, ação sobre a saúde humana, benefícios sociais, econômicos e fisiológicos, assim como utilização para alimentação, remédios medicinais e, inclusive, a redução da violência doméstica e índices de criminalidades (GALVIN, 1999; MILANO; DALCIN, 2000; MASCARÓ; MASCARÓ, 2002; DILLEY; WOLF, 2014).

Para a seleção de árvores para compor a arborização viária é necessário considerar uma série de características, como porte, copa (forma, densidade e hábito), desenvolvimento, floração, frutificação, sistema radicular, resistência a pragas, doenças e poluição, ausência de princípios fitotóxicos ou alérgicos (GOMES, 2012).

O zoneamento urbano é um dos principais instrumentos para planejamento da arborização viária. É visível e compreensível que as zonas comerciais apresentam os maiores impactos negativos sobre a arborização viária quando comparados às zonas residenciais, pois são espaços urbanos com maior fluxo de veículos, pedestres e edificações com ausência de recuo frontal, o que acaba desencadeando interferências negativas com a copa das árvores.

Com isso, o planejamento da arborização de acompanhamento viário deve ser realizado de acordo com as características dendrológicas das espécies e, principalmente, de acordo com os componentes da infraestrutura urbana localizados no nível subterrâneo, superficial ou aéreo, ou seja, deve haver uma correlação entre espaço e entorno, bem como uma profunda avaliação sobre as distâncias e dimensionamento dos componentes presentes nestes três níveis.

Neste contexto, o presente trabalho teve por objetivo avaliar a situação atual da arborização de acompanhamento viário, em uma zona comercial na cidade de Maringá, Estado do Paraná, a saber: Zona de Comércio Central (ZCC).

\section{MATERIAIS E MÉTODOS}

O método baseou-se em uma pesquisa exploratória e descritiva, com abordagem qualitativa e quantitativa. Como procedimento, realizou-se uma pesquisa 
bibliográfica, documental e de levantamento censo, ou seja, todas as árvores e edificações que possuem árvores em sua face foram inventariadas.

\subsection{CARACTERIZAÇÃO DA ÁREA DE ESTUDO}

A ZCC ou Zona 01 (Figura 1) localiza-se na Região Central de Maringá, delimitada pelas Av. Tiradentes, Av. Cidade de Leiria, Av. Pedro Taques, Av. Laguna e Av. Tamandaré. Outro trecho delimitado pela Av. João Paulino Vieira Filho, Av. Paraná, Av. São Paulo e Av. Prudente de Moraes. Possui 62 quadras, 1.237 lotes e área total de 1.284.439,20 $\mathrm{m}^{2}$. Predominam funções diversificadas, compreendendo os seguintes usos: comércios e serviços centrais e vicinais e uso residencial unifamiliar, bifamiliar e multifamiliar; pequenas indústrias e atacados não incômodos, nocivos ou perigosos (MARINGÁ, 2016).

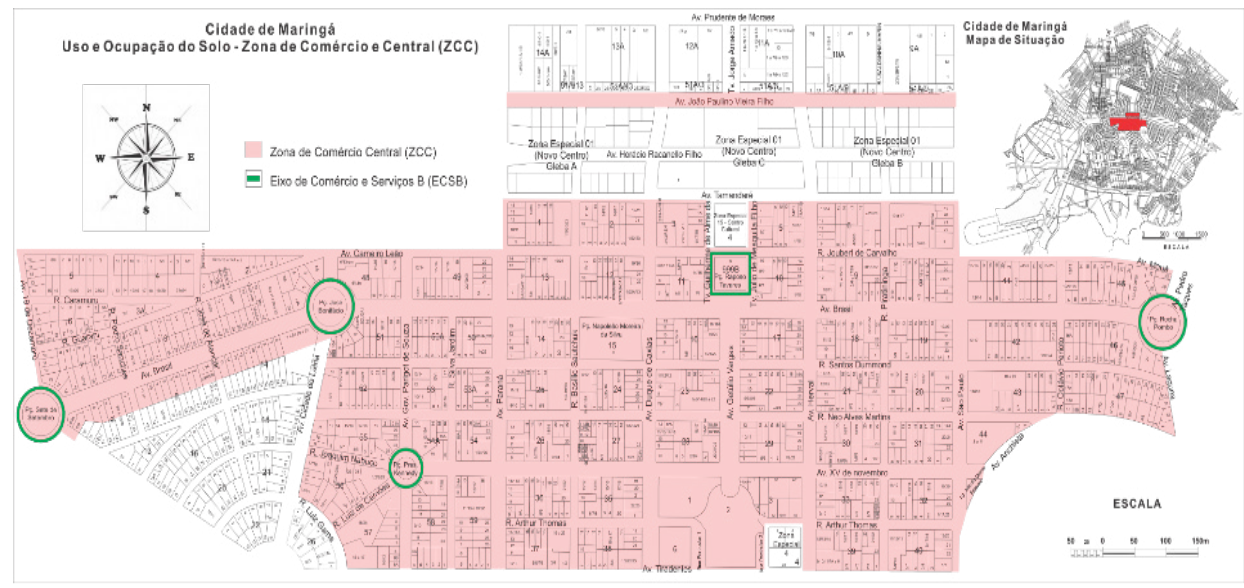

Figura 1. Mapa de localização e uso e ocupação do solo da Zona de Comércio Central. Fonte: Adaptado de Maringá (2015).

\subsection{LEVANTAMENTO QUALIQUANTITATIVO}

Para identificar as árvores, utilizou-se a metodologia usual taxonômica e consulta bibliográfica baseada em Lorenzi (2002; 2008) e Lorenzi et al. (2003). A identificação foi feita por meio do reconhecimento visual, com observação de 
caracteres botânicos e dendrológicos. As espécies que não puderem ser identificadas tiveram troncos, folhas, galhos, flores e, por ventura, frutos fotografados e posteriormente identificados.

As espécies identificadas foram classificadas segundo a sua procedência e status de invasão (Quadro 1), segundo Sampaio (2013).

Quadro 1. Identificação das espécies segundo procedência e categorias de status de invasão

\begin{tabular}{|l|l|}
\hline \multicolumn{1}{|c|}{ Procedência } & \multicolumn{1}{c|}{ Categorias de status de invasão } \\
\hline $\begin{array}{l}\text { Exóticas extra brasileiras (ex-BR): } \\
\text { originária de outros países. }\end{array}$ & $\begin{array}{l}\text { Introduzida (Int): espécie trazida de outras regióes, cujos in- } \\
\text { divíduos conseguem se desenvolver, mas sem reproduzir-se } \\
\text { no novo ambiente onde foram introduzidos. }\end{array}$ \\
\hline $\begin{array}{l}\text { Exótica extra paranaense (ex-PR): } \\
\text { originária de outros Estados. }\end{array}$ & $\begin{array}{l}\text { Estabelecida (Est): espécie trazida de outras regiões e que } \\
\text { consegue se reproduzir no novo ambiente, podendo ou não } \\
\text { tornar-se uma invasora. }\end{array}$ \\
\hline $\begin{array}{l}\text { Exótica extra Floresta Estacional } \\
\text { Semidecidual paranaense (ex-FES } \\
\text { PR): espécie que não ocorre espon- } \\
\text { taneamente na Floresta Estacional. }\end{array}$ & $\begin{array}{l}\text { Invasora (Inv): espécie trazida de outras regiões e da qual já } \\
\text { exista registros de invasão no Brasil. }\end{array}$ \\
\hline $\begin{array}{l}\text { Nativa (Nat): espécie típica de Flo- } \\
\text { resta Estacional Semidecidual. }\end{array}$ & $\begin{array}{l}\text { Desconhecida (Des): espécies da qual ainda não existem re- } \\
\text { gistros como estabelecidas ou invasoras, não se podendo, no } \\
\text { entanto, descartar tais possibilidades. }\end{array}$ \\
\hline
\end{tabular}

Fonte: Adaptado de Sampaio (2006); Paraná (2015).

A avaliação qualitativa da arborização viária levou em consideração quatro itens, sendo local de plantio, sistema radicular, copa e poda, como se observa no Quadro 2.

O item local de plantio (I) refere-se à posição das árvores em relação ao lote, ou seja, meio do lote, divisa do lote, entre meio e divisa do lote. Verificou-se também a proximidade com poste e esquina.

A definição da proximidade com a esquina foi estabelecida conforme normas da Prefeitura Municipal de Maringá, sendo mantida uma distância de 4,0 m para espécies de pequeno, médio e porte grande. A proximidade com o poste seguiu as diretrizes da Copel (COMPANHIA PARANAENSE DE ENERGIA, 2009), sendo mantida uma distância de 3,0 m para espécies de pequeno porte, 4,0 $\mathrm{m}$ de porte médio e 5,0 $\mathrm{m}$ de porte alto. 
No item sistema radicular (L), observou-se qual o comportamento da raiz, ou seja, se estão totalmente subterrâneas ou superficiais. No caso de superficiais, verificou-se rachaduras nas calçadas e nas edificações.

Em relação à copa $(\mathrm{M})$, verificou-se aquelas em condições adequadas, ou seja, que não causam interferências nas edificações. Observou-se aquelas copas que causam conflitos com pedestres, edificações e trânsito de veículos, bem como aquelas que estão descaracterizadas, devido às podas drásticas.

No item poda (N) observou-se aquelas árvores onde houve podas anteriores, seja de formação, manutenção ou emergência. Verificaram-se podas com brotos, podas drásticas, podas fachadas e edificações, ou seja, ocorrida devido a algum conflito com equipamentos urbanos. Quando não houve o anel de cicatrização, chegou-se à conclusão que não ocorreram podas.

Quadro 2. Planilha explicativa para coleta de dados da arborização viária

\begin{tabular}{|l|l|}
\hline \multicolumn{2}{|c|}{ Arborização de acompanhamento viário } \\
\hline Identificação da espécie (H) \\
\hline H1 & $\begin{array}{l}\text { Nome popular e científico do exemplar arbóreo: para identificação da nomenclatura das } \\
\text { árvores utilizou-se metodologia usual taxonômica e consulta bibliográfica baseada em Lo- } \\
\text { renzi (2002; 2008); Lorenzi et al. (2003). }\end{array}$ \\
\hline \multicolumn{2}{|l|}{ Local de plantio (I) } \\
\hline I1 & No meio do lote: quando a árvore está plantada no meio do lote. \\
\hline I2 & Na divisa de lotes: quando a árvore está plantada na divisa de lotes. \\
\hline I3 & $\begin{array}{l}\text { Entre meio do lote e divisa: quando a árvore está plantada entre meio do lote e divisa de } \\
\text { lotes. }\end{array}$ \\
\hline I4 & $\begin{array}{l}\text { Árvore plantada próximo à esquina: quando a árvore está plantada em até 4,00 m da } \\
\text { esquina. }\end{array}$ \\
\hline I5a & Próximo ao poste: quando a árvore está plantada próximo ao posteamento. \\
\hline & \multicolumn{1}{|c|}{ Sistema radicular (L) } \\
\hline L1 & Raiz totalmente subterrânea: raiz sem afloramento. \\
\hline L2 & $\begin{array}{l}\text { Raiz superficial somente na área de crescimento da árvore: raiz superficial somente den- } \\
\text { tro da área de crescimento da árvore imposta pelo calçamento. }\end{array}$ \\
\hline L3 & $\begin{array}{l}\text { Raiz superficial provocando rachaduras nas calçadas: raiz superficial, ultrapassando a área } \\
\text { de crescimento e provocando rachaduras nas calçadas. }\end{array}$ \\
\hline L4 & $\begin{array}{l}\text { Raiz superficial provocando rachaduras nas edificações: raiz superficial, ultrapassando a } \\
\text { área de crescimento e provocando rachaduras em muros e/ou edificações. }\end{array}$ \\
\hline
\end{tabular}




\begin{tabular}{|l|l|}
\hline \multicolumn{2}{|c|}{ Copa (M) } \\
\hline \multicolumn{2}{|c|}{ Arborização de acompanhamento viário } \\
\hline M1 & Copa adequada: quando a copa não causa interferências nas edificações. \\
\hline M2 & $\begin{array}{l}\text { Copa em conflito com pedestres: quando a copa estiver de alguma maneira interferindo o } \\
\text { passeio de pedestres. }\end{array}$ \\
\hline M3 & $\begin{array}{l}\text { Copa em conflito com edificação: quando a copa estiver de alguma maneira dividindo } \\
\text { espaço com as edificações. }\end{array}$ \\
\hline M4 & $\begin{array}{l}\text { Copa em conflito com trânsito de veículos: quando a copa estiver de alguma maneira inter- } \\
\text { ferindo o trânsito de veículos. }\end{array}$ \\
\hline M5 & Copa ausente e/ou descaracterizada: não há copa evidente e/ou copa descaracterizada. \\
\hline & \multicolumn{1}{|c|}{ Poda (N) } \\
\hline N1 & $\begin{array}{l}\text { Poda anterior: quando é visível que foi realizado poda, e que não há rebrotas. A poda } \\
\text { anterior quer dizer que se refere àquela poda realizada de forma correta, seja poda de } \\
\text { formação, manutenção ou emergência. }\end{array}$ \\
\hline N2 & Poda com brotos: quando é viśivel que foi realizado poda, mas há rebrotas. \\
\hline N3 & Não há indícios de poda: quando a árvore está ausente de anel de cicatrização. \\
\hline N4 & Poda drástica: quando a poda foi drástica ou galhos em excesso foram retirados. \\
\hline N5 & $\begin{array}{l}\text { Poda edificação: quando ocorreu poda devido ao conflito com as edificações (poda de } \\
\text { adequação). }\end{array}$ \\
\hline N6 & $\begin{array}{l}\text { Poda fachada: quando é evidente que ocorreu poda devido ao conflito com as fachadas } \\
\text { comerciais (poda de adequação). }\end{array}$ \\
\hline
\end{tabular}

Fonte: Adaptado de Milano (1988) e Sampaio (2006).

Com base no Quadro 2 e como forma de facilitar o levantamento em campo elaborou-se uma planilha, designada "levantamento in loco", que teve por objetivo sintetizar os dados, atribuindo-se uma legenda para cada parâmetro avaliado. Os dados obtidos foram agrupados em um banco de dados em software apropriado, onde foram compilados, processados e representados.

\section{RESULTADO E DISCUSSÃO}

Identificou-se um total de 1.758 exemplares arbóreos de 57 espécies. Verificou-se a predominância de Caesalpinia pluviosa var. peltophoroides (Benth) G. P. Lewis (sibipiruna) (36,6\%) Tipuana tipu (Benth.), Kuntze (tipuana) (20,4\%) e Holocalyx balansae Micheli (alecrim de Campinas) (15,8\%), que na totalidade 
representam $72,9 \%$ do total. A Tabebuia avellanedae Lor. Ex Griseb. (Ipê roxo), símbolo da cidade de Maringá, registrou 0,9\% do total (Quadro 1).

Quadro 1. Relação das espécies ocorrentes na ZCC, na cidade de Maringá (PR) (Continua)

\begin{tabular}{|c|c|c|c|c|}
\hline Nome Popular & Nome Científico & Família & Procedência & Qtde \\
\hline Abacateiro & Persea gratissima Mill. & Lauraceae & Ex-BR-inv. & 1 \\
\hline Açoita Cavalo & Luechea divaricata Mart. & Tiliaceae & Nativa & 1 \\
\hline Aldrago & Pterocarpus violaceus Vogel & $\begin{array}{l}\text { Leguminosae-Papilio- } \\
\text { noideae (Fabaceae) }\end{array}$ & Nativa & 17 \\
\hline $\begin{array}{l}\text { Alecrim de Cam- } \\
\text { pinas }\end{array}$ & Holocalyx balansae Micheli & $\begin{array}{l}\text { Leguminosae-Caesal- } \\
\text { pinoideae (Caesalpi- } \\
\text { naceae) }\end{array}$ & Nativa & 278 \\
\hline Aleluia & $\begin{array}{l}\text { Senna multijuga (Rich.) H.S. Irwin } \\
\text { \& Barneby }\end{array}$ & $\begin{array}{l}\text { Leguminosae-Caesal- } \\
\text { pinoideae (Caesalpi- } \\
\text { naceae) }\end{array}$ & Nativa & 1 \\
\hline Alfeneiro da China & Ligustrum sinense Lour. & Oleaceae & Ex-BR & 1 \\
\hline Aroeira Pimenta & Schinus terebinthifolia Raddi & Anacardiaceae & Nativa & 28 \\
\hline Aroeira Salsa & Schinus molle $\mathrm{L}$ & Anacardiaceae & Nativa & 8 \\
\hline Astrapéia & $\begin{array}{l}\text { Dombeya wallichii (Lindl.) K. } \\
\text { Schum. }\end{array}$ & Malvaceae & Ex-BR & 7 \\
\hline Cabreúva & Myrocarpus peruiferum L. f. & $\begin{array}{l}\text { Leguminosae-Papilio- } \\
\text { noideae (Fabaceae) }\end{array}$ & Nativa & 28 \\
\hline Caju & Anacardium occidentable $\mathrm{L}$. & Anacardiaceae & Nativa & 1 \\
\hline Calistemun & Callistemon sp. & Myrtaceae & Ex-BR & 3 \\
\hline Canelinha & $\begin{array}{l}\text { Nectandra megapotamica (Spr.) } \\
\text { Mez }\end{array}$ & Lauraceae & Nativa & 1 \\
\hline Caroba & Jacaranda micrantha cham. & Bignoniaceae & Nativa & 24 \\
\hline Carobinha & Jacaranda puberula cham & Bignoniaceae & Nativa & 1 \\
\hline Cássia Rósea & Cassia grandis Linnaeus $\mathrm{F}$. & $\begin{array}{l}\text { Leguminosae-Caesal- } \\
\text { pinoideae (Caesalpi- } \\
\text { naceae) }\end{array}$ & $\mathrm{Ex}-\mathrm{BR}$ & 1 \\
\hline Cedro & Cedrela fissilis Vell. & Meliaceae & Nativa & 2 \\
\hline Chá de bugre & Cordia sellowiana Cham. & Boraginaceae & Nativa & 1 \\
\hline Chuva d ouro & Cassia fistula $\mathrm{L}$. & $\begin{array}{l}\text { Leguminosae-Caesal- } \\
\text { pinoideae (Caesalpi- } \\
\text { naceae) }\end{array}$ & $\mathrm{Ex}-\mathrm{BR}$ & 3 \\
\hline Embaúba & Cecropia pachystachya Trécul & Cecropiaceae & Nativa & 1 \\
\hline Eucalípto & Eucalyptus sp. & Myrtaceae & Ex-BR-est. & 1 \\
\hline Falsa Murta & Murraya paniculata (L.) Jack & Rutaceae & Ex-BR & 11 \\
\hline
\end{tabular}


(Continua)

\begin{tabular}{|c|c|c|c|c|}
\hline Nome Popular & Nome Científico & Família & Procedência & Qtde \\
\hline Falso Pau Brasil & Caesalpinia sappan $\mathrm{L}$. & $\begin{array}{l}\text { Leguminosae-Caesal- } \\
\text { pinoideae (Caesalpi- } \\
\text { naceae) }\end{array}$ & Ex-BR & 1 \\
\hline Ficus & Ficus benjamina $\mathrm{L}$. & Moraceae & Ex-BR & 2 \\
\hline Figueira Chorão & Ficus celebensis Corner & Moraceae & Ex-BR & 1 \\
\hline Flamboyant & $\begin{array}{l}\text { Delonix regia (Bojer ex Hook.) } \\
\text { Raf. }\end{array}$ & Fabaceae & Ex-BR & 2 \\
\hline Fruta do conde & Annona squamosa L. & Annonaceae & Ex-BR & 3 \\
\hline Ipê Amarelo & $\begin{array}{l}\text { Tabebuia chrysotricha (Mart. Ex } \\
\text { DC.) Standl }\end{array}$ & Bignoniaceae & Nativa & 60 \\
\hline Ipê Branco & $\begin{array}{l}\text { Tabebuia roseo-alba (Ridl.) San- } \\
\text { dwith }\end{array}$ & Bignoniaceae & Nativa & 24 \\
\hline Ipê Rosa & $\begin{array}{l}\text { Tabebuia impetiginosa (Mart. Ex } \\
\text { DC.) Standl. }\end{array}$ & Bignoniaceae & Nativa & 54 \\
\hline Ipê Roxo & $\begin{array}{l}\text { Tabebuia avellanedae Lor. Ex } \\
\text { Griseb. }\end{array}$ & Bignoniaceae & Nativa & 17 \\
\hline Jacarandá & Jacaranda mimosifolia D. Don & Bignoniaceae & Exótica & 39 \\
\hline $\begin{array}{l}\text { Jacarandá boca de } \\
\text { sapo }\end{array}$ & Jacaranda brasiliana (Lam.) Pers. & Bignoniaceae & Nativa & 1 \\
\hline Jasmin Manga & Plumeria Rubra L. & Apocynaceae & Ex-BR & 1 \\
\hline Leucena & $\begin{array}{l}\text { Leucaena leucocephala (Lam.) R. } \\
\text { de Wit }\end{array}$ & $\begin{array}{l}\text { Leguminosae-mimo- } \\
\text { soideae }\end{array}$ & Ex-BR-inv. & 2 \\
\hline Ligustro & Ligustrum lucidum W. T. Aiton & Oleaceae & Ex-BR-inv. & 18 \\
\hline Limão & Citrus sp. & Rutaceae & Ex-BR-est. & 1 \\
\hline Mamão & Carica papaya $\mathrm{L}$ & Caricaceae & Ex-BR-inv. & 2 \\
\hline Manacá da serra & Tibouchina mutabilis Cogn. & Melastomaceae & Nativa & 5 \\
\hline Mangueira & Mangifera indica $\mathrm{L}$. & Anacardiaceae & Ex-BR-inv. & 3 \\
\hline Não Identificada & - & - & - & 1 \\
\hline Oiti & $\begin{array}{l}\text { Licania tomentosa (Benth.) } \\
\text { Fritsch }\end{array}$ & Chrysobalanaceae & Nativa & 53 \\
\hline $\begin{array}{l}\text { Palmeira Areca de } \\
\text { locuba }\end{array}$ & $\begin{array}{l}\text { Archontophoenix cf. alexandrae } \\
\text { (F. Muell.) H. Wendl, \& Drude }\end{array}$ & Arecaceae & Ex-BR & 1 \\
\hline Palmeira Imperial & $\begin{array}{l}\text { Roystonea oleracea (Jacq.) O. F. } \\
\text { Cook }\end{array}$ & Arecaceae & $\mathrm{Ex}-\mathrm{BR}$ & 5 \\
\hline Palmeira Real & $\begin{array}{l}\text { Archontophoenix cf. alexandrae } \\
\text { (F. Muell.) H. Wendl, \& Drude }\end{array}$ & Arecaceae & $\mathrm{Ex}-\mathrm{BR}$ & 1 \\
\hline
\end{tabular}


(Conclusão)

\begin{tabular}{|c|c|c|c|c|}
\hline Nome Popular & Nome Científico & Família & Procedência & Qtde \\
\hline Pata de vaca & Baubinia Variegata L. & $\begin{array}{l}\text { Leguminosae-Caesal- } \\
\text { pinoideae (Caesalpi- } \\
\text { naceae) }\end{array}$ & $\mathrm{Ex}-\mathrm{BR}$ & 1 \\
\hline Pau Brasil & Caesalpinia echinata Lam. & $\begin{array}{l}\text { Leguminosae-Caesal- } \\
\text { pinoideae (Caesalpi- } \\
\text { naceae) }\end{array}$ & Nativa & 21 \\
\hline Pau Ferro & $\begin{array}{l}\text { Caesalpinia paraguariensis (Pa- } \\
\text { rodi) Burk. }\end{array}$ & $\begin{array}{l}\text { Leguminosae-Caesal- } \\
\text { pinoideae (Caesalpi- } \\
\text { naceae) }\end{array}$ & Nativa & 2 \\
\hline Pitanga & Eugenia uniflora $\mathrm{L}$. & Myrtaceae & Nativa & 2 \\
\hline Quaresmeira & $\begin{array}{l}\text { Tibouchina granduosa (Desr.) } \\
\text { Cogn. }\end{array}$ & Melastomaceae & Nativa & 3 \\
\hline Resedá & Lagerstroemia indica $\mathrm{L}$. & Lythraceae & Ex-BR & 4 \\
\hline Romã & Punica granatum $\mathrm{L}$ & Punicaceae & Ex-BR & 1 \\
\hline Sabão de Soldado & Sapindus saponaria $\mathrm{L}$. & Sapindaceae & Nativa & 1 \\
\hline Sete Copas & Terminalia catappa $\mathrm{L}$. & Combretaceae & Ex-BR & 1 \\
\hline Sibipiruna & $\begin{array}{l}\text { Caesalpinia pluviosa var. pel- } \\
\text { tophoroides (Benth) G. P. Lewis }\end{array}$ & $\begin{array}{l}\text { Leguminosae-Caesal- } \\
\text { pinoideae (Caesalpi- } \\
\text { naceae) }\end{array}$ & Nativa & 644 \\
\hline Sombreiro & $\begin{array}{l}\text { Clitoria fairchildiana R.A. How- } \\
\text { ard }\end{array}$ & $\begin{array}{l}\text { Leguminosae-Papilio- } \\
\text { noideae (Fabaceae) }\end{array}$ & Nativa & 1 \\
\hline Tipuana & Tipuana tipu (Benth.) Kuntze & $\begin{array}{l}\text { Leguminosae-Papilio- } \\
\text { noideae (Fabaceae) }\end{array}$ & Ex-BR & 360 \\
\hline Total & & & & 1758 \\
\hline
\end{tabular}

De acordo com os resultados apresentados por Milano (1988), aproximadamente $63,0 \%$ das árvores eram de sibipirunas e 34,2\% de tipuanas. Sampaio (2006) identificou na Zona 01 que aproximadamente 39,0\% das árvores eram representadas por sibipirunas e $18,0 \%$ por tipuanas. Na pesquisa atual, observou-se na ZCC que a frequência de sibipirunas é bem próxima de Sampaio (2006) onde tem-se 36,6\% de sibipirunas e 20,4\% de tipuanas. Ou seja, decorridos dez anos, verificou-se que a frequência de sibipirunas e tipuanas manteve-se em um mesmo patamar.

$\mathrm{Na}$ pesquisa atual, observou-se uma distribuição desigual de determinadas espécies. Das 36,6\% das sibipirunas, aproximadamente 23,0\% localizam-se na Av. 
Brasil. Aproximadamente $\mathbf{7 5 , 0 \%}$ das tipuanas estão localizadas em dois logradouros: Rua Santos Dumont e Av. XV de novembro. Isso demonstra um problema que consiste na elevada frequência da espécie e na sua distribuição ao longo da ZCC. Ou seja, a riqueza de espécies vegetais na área de estudo é correntemente alta, porém mal distribuída.

O que se percebe em Maringá, precisamente na ZCC, é uma alteração nas árvores dos passeios públicos, quando comparada à prática da Companhia Melhoramento Norte do Paraná (CMNP) no seu plano original. Inicialmente, plantavam-se principalmente tipuanas, sibipirunas, ipês, bisnaqueiras e jacarandás (BELOTO; DE ANGELIS, 2003). Nos dias de hoje, constata-se uma mudança com o plantio de aldrago, alecrim de Campinas, aroeira-salva, cabreúva, canelinha, cerejeira Japão, acácia-amarela, flamboyant-amarelo, ipê amarelo, ipê branco, manacá da serra, mirindiba, oiti, copaíba, palmeira cariota, palmeira imperial, palmeira real, palmeira tamareira, pata-de-vaca, tamarindo, quaresmeira, resedá e saboneteira (MARINGÁ, 2016b).

O planejamento da arborização deveria contemplar uma diversidade com distribuição heterogênea e equilibrada ao longo das quadras, como forma de atração paisagística e biodiversidade de avifauna. Normalmente nas ruas e avenidas da ZCC estão concentradas, principalmente, uma ou duas espécies. Assim na Av. João Paulino predomina o ipê amarelo, na Av. Brasil predomina a sibipiruna, na Rua Neo Alves Martins os alecrins de Campinas, na Rua Santos Dumont e Av. XV de novembro as tipuanas.

\subsection{LOCAL DE PLANTIO DAS ÁRVORES}

Em relação ao local de plantio, os resultados demonstram que 33,2\% das árvores estão plantadas no meio do lote na ZCC e 27,9\% estão plantadas entre o meio de lote e divisa (Tabela 1). 
Tabela 1. Local de plantio em relação ao lote na ZCC, ZR2 e ZE1 - frequência relativa de ocorrência (FR\%) e quantidade (Un.)

\begin{tabular}{lcc|}
\hline \multirow{2}{*}{\multicolumn{1}{c}{ Local de plantio (em relação ao lote) }} & \multicolumn{2}{c|}{ ZCC } \\
\cline { 2 - 3 } & Un. & $\%$ \\
\hline Plantio no meio do lote & 584 & 33,2 \\
\hline Plantio na divisa de lotes & 394 & 22,4 \\
\hline Plantio entre meio de lote e divisa & 491 & 27,9 \\
\hline Plantio próximo a esquina & 289 & 16,4 \\
\hline Total & 1758 & 100,0 \\
\hline
\end{tabular}

Este estudo permitiu estabelecer que as árvores plantadas na divisa dos lotes apresentaram as menores danificações e podas drásticas, em função do recuo lateral das edificações. Deste modo, há uma relação bem próxima entre edificações e arborização na ZCC.

\subsection{SISTEMA RADICULAR}

Na ZCC observou-se que 67,0\% das árvores estão com raízes sem afloramento no passeio subterrâneo, porém aproximadamente $30,0 \%$ provocam rachaduras nos passeios (Tabela 2).

Tabela 2. Características do sistema radicular na ZCC, ZR2 e ZE1 - frequência relativa de ocorrência (FR\%) e quantidade (Un.)

\begin{tabular}{lcc|}
\hline \multirow{2}{*}{ Caracterização do sistema radicular } & \multicolumn{2}{c|}{ ZCC } \\
\cline { 2 - 3 } & Un. & $\%$ \\
\hline Raiz totalmente subterrânea & 1179 & 67,0 \\
\hline Raiz superficial somente na área de crescimento da árvore & 50 & 2,8 \\
\hline $\begin{array}{l}\text { Raiz superficial, ultrapassando a área de crescimento da árvore, provo- } \\
\text { cando rachaduras nas calçadas }\end{array}$ & 526 & 29,9 \\
\hline $\begin{array}{l}\text { Raiz superficial, ultrapassando a área de crescimento da árvore, provo- } \\
\text { cando rachaduras nas construções }\end{array}$ & 3 & 0,1 \\
\hline Total & 1758 & 100,0 \\
\hline
\end{tabular}


Sampaio (2006) identificou na área do Plano Piloto de Maringá que 45,6\% das árvores registradas apresentaram raízes que não estavam afetando as calçadas de forma nenhuma, ou seja, totalmente subterrâneas ou sistema radicular somente na área de crescimento das árvores. Na pesquisa atual constata-se que este percentual está em 69,9\%, ou seja, houve uma melhora significativa nos últimos dez anos, possivelmente relacionada à padronização dos passeios e o aumento da área livre permeável para 2,88 m² (1,20 m x 2,40 m), pela Lei Complementar $\mathrm{n}^{\mathrm{o}}$ 910/2011 e NRM U-20001/2016 (MARINGÁ, 2016a).

Sampaio (2006) identificou que 53,8\% das árvores estavam com afloramento destruindo calçadas de forma evidente. Na pesquisa atual, observa-se que este percentual apresentou queda para 29,9\%. Em 2006 raízes que afetavam construções (muros ou edificações) estavam com um percentual de $0,4 \% \mathrm{e}$, atualmente, com $0,1 \%$.

Nesta pesquisa, 48,2\% das sibipirunas e 55,8\% da tipuanas apresentaram raízes totalmente subterrâneas. Verificou-se que 47,3\% das sibipirunas e 39,4\% das tipuanas provocam rachaduras nas calçadas e, consequentemente, perigo aos transeuntes. Com relação aos alecrins de Campinas, 89,9\% apresentaram raízes totalmente subterrâneas. Das dez espécies de maior frequência a única que apresentou 100,0\% das raízes subterrâneas foi o ipê amarelo. Acima de 90,0\% dos oitis, aroeiras pimenta, cabreúvas e ipês branco possuem sistema radicular totalmente subterrânea.

Com base nos dados apresentados, pode-se afirmar que as espécies mais antigas como tipuanas e sibipirunas são as que possuem sistema radicular que provocam os maiores danos às calçadas. Considera-se que estes dados estão relacionados às características do sistema radicular destas espécies, mas, principalmente à ausência de área permeável no entorno da árvore.

Espécies que possuem sistema radicular exposto, com danificação de calçadas tendem a causar uma série de impactos negativos de acessibilidade, que podem ocasionar, inclusive, acidentes.

De acordo com Balensiefer e Wiecheteck (1985) as espécies mais indicadas para a arborização são as que apresentam sistema radicular pivotante e profundo. Porém, nada impede que sejam plantadas árvores de raízes superficiais, desde que 
haja uma ampla área livre permeável, para desenvolvimento adequado das raízes.

Mesmo não sendo obrigatória a presença de calçadas ecológicas na ZCC, observou-se que nos locais onde há este tipo de calçada, o sistema radicular das árvores apresentou-se totalmente subterrânea, não causando nenhum impacto a acessibilidade dos transeuntes.

\subsection{COPA}

A copa das árvores talvez seja aquela parte que mais forneça vantagens ambientais para as cidades, transeuntes e edificações. O sombreamento proporcionado pelas copas minimiza o calor em dias de elevadas temperaturas, diminuem as temperaturas superficiais dos pavimentos, edificações e fachadas e contribui com o deslocamento dos transeuntes.

Segundo Mascaró (2002), o sombreamento, dependendo da espécie, está relacionado com transmitância luminosa, permeabilidade do vento, regulação da temperatura e da umidade relativa do ar.

Em situação oposta, a copa das árvores, quando indevidamente planejada, talvez seja aquela parte que mais causa impactos negativos nas cidades, aos transeuntes e às edificações. São evidentes as interferências negativas com as edificações, que podem interferir na iluminação natural interna e causar entupimento do sistema de drenagem pluvial. Da mesma forma em que há relatos de munícipes que se sentem incomodados com a alta quantidade de folhas e flores que caem no seu ciclo natural.

De acordo com Balensiefer e Wiecheteck (1985) a dimensão da copa das árvores deve ser compatível com o espaço físico do entorno, permitindo o livre trânsito de veículos e pedestres, e evitando possíveis danos às edificações e fachadas.

Esta pesquisa avaliou as características da copa das árvores e observou-se que na ZCC 75,0\% das copas não causam interferências em edificações, veículos ou fluxo de pedestres. Porém, verificou-se que 20,0\% das copas estão interferindo negativamente nas edificações (Tabela 3). 
Tabela 3. Características da copa das árvores na ZCC frequência relativa de ocorrência (FR\%) e quantidade (Un.)

\begin{tabular}{lcc}
\hline \multicolumn{1}{c}{ Copa } & Exemplares & $\%$ \\
\hline Copa adequada & 1309 & 74,4 \\
\hline Copa em conflito com pedestres & 24 & 1,3 \\
\hline Copa em conflito com edificações & 356 & 20,2 \\
\hline Copa em conflito com trânsito de veículos & 35 & 1,9 \\
\hline Copa ausente ou descaracterizada & 34 & 1,9 \\
\hline Total & 1758 & 100,0 \\
\hline
\end{tabular}

\subsection{PODA}

Os dados referentes às podas demonstraram que na ZCC, em vista de uma área antiga sob o ponto de vista urbanístico apresentou $40,7 \%$ de poda anterior sem rebrotas; $26,0 \%$ de poda ocorrida devido ao conflito com edificações e $19,0 \%$ são de árvores em que não há indícios de poda.

Segundo dados de Milano (1988), a maior frequência de danos físicos provocados por poda ocorreu em regiões central da cidade ${ }^{6} \operatorname{com} 67,1 \%$. São regiões densamente ocupadas, estando relacionadas com as necessidades de controle do tamanho e forma das copas das árvores que competem espaço com edificações, marquises, placas e fachadas comerciais. Verificou-se um maior percentual de podas drásticas executadas na arborização viária quando comparada aos canteiros centrais, onde a dificuldade de compatibilização entre porte e espaço disponível é extremamente difícil.

Sampaio (2006) registrou na área do plano piloto da cidade de Maringá que 269 árvores tinham sofrido poda drástica. Na pesquisa atual identificou-se que na ZCC que 78 exemplares apresentaram podas drásticas, o que indica que as podas desse tipo, prejudiciais às árvores, estão sendo pouco aplicadas na região central da cidade de Maringá. Destas, aproximadamente 58,0\% são de sibipirunas e 20,5\% são de tipuanas. A execução das podas drásticas ocorreu em árvores que estão sob a fiação elétrica e naquelas edificações que estão no alinhamento predial. Nas árvores

$6 \quad$ Os dados apresentados referem-se à amostra 186, que corresponde a uma área de 200x500 m dentro da atual ZCC. 
localizadas na face das edificações com recuo predial não houve ocorrência de podas drásticas, o que indica que este tipo de poda não está relacionado essencialmente e à rede elétrica, mas também, às características das edificações.

$\mathrm{Na}$ ZCC houve 445 casos de poda ocorrida devido ao conflito com as edificações, sendo que em 352 delas as edificações estão localizadas junto ao alinhamento predial. Verificou-se 44 casos de poda ocorrida devido ao conflito com fachadas comerciais (Tabela 4). Destas, 61,3\% são de sibipirunas, 13,6\% aldrago e 11,3\% de alecrins. A espécie aldrago devido à característica irregular da copa apresentou incompatibilidade com as fachadas comerciais, o que indica que talvez não seja a melhor espécie para ser plantada em uma zona essencialmente comercial.

Tabela 4. Características da poda de árvores na ZCC frequência relativa de ocorrência (FR\%) e quantidade (Un.)

\begin{tabular}{lcc}
\hline \multicolumn{1}{c}{ Poda } & Exemplares arbóreos & $\%$ \\
\hline Poda anterior sem rebrotas & 717 & 40,7 \\
\hline Poda anterior com rebrotas & 118 & 6,7 \\
\hline Sem poda anterior & 343 & 19,5 \\
\hline Com poda drástica & 78 & 4,4 \\
\hline Poda ocorrida devido conflito com edificações & 458 & 26,0 \\
\hline Poda ocorrida devido às fachadas comerciais & 44 & 2,5 \\
\hline Total & 1758 & 100,0 \\
\hline
\end{tabular}

\section{CONSIDERAÇÕES FINAIS}

Os resultados indicaram a existência de 1.758 exemplares arbóreos de 57 espécies, dos quais $72,9 \%$ do total são de apenas três espécies: sibipirunas, tipuanas e alecrim de Campinas.

Observou-se que a riqueza de espécies vegetais na área de estudo é correntemente alta, porém mal distribuída. Neste caso, o planejamento da arborização deveria contemplar uma diversidade com distribuição heterogênea e equilibrada ao longo das quadras.

Nota-se que em zonas comerciais há uma maior ocorrência de impactos 
negativos das copas sobre as edificações. Assim, observou-se que 26,0\% das árvores apresentaram poda ocorrida devido ao conflito com edificações. Tais dados, vêm ao encontro do diagnóstico realizado nas copas das árvores, onde $20,0 \%$ das copas estão interferindo negativamente nas edificações.

Portanto, com base nos dados levantados, pode-se afirmar que tanto sob aspectos quantitativos quanto qualitativos a situação da arborização urbana da ZCC é preocupante, pois há uma alta incidência de poucas espécies que causam uma série de impactos negativos sob as edificações.

\section{AGRADECIMENTOS}

À Coordenação de Aperfeiçoamento de Pessoal de Nível Superior (CAPES), pela disponibilização de bolsa de estudo de doutorado.

\section{REFERÊNCIAS}

BALENSIEFER, M.; WIECHETECK, M. Arborização de cidades. Curitiba: Governo do Paraná, Instituto de Terras e Cartografia, 1985.

BELOTO, G. E.; DE ANGELIS, B. L. Arborização urbana e sua relação com o uso do solo na cidade de Maringá, Estado do Paraná. Acta Scientiarum. Technology, v. 25, no. 1, p. 103-111, 2003.

COMPANHIA PARANAENSE DE ENERGIA. Arborização de vias públicas. Curitiba: COPEL, 2009. Disponível em: http://www.copel.com/hpcopel/guia_arb/como_planejar_a_arborizacao.html. Acesso em: 23 nov. 2015.

DILLEY, J.; WOLF, K. Homeowner interactions with residential tress in urban areas. Arboriculture \& Urban Forestry, v. 39, n. 6, p. 267-277, abr. 2014. Disponível em: http://joa.isa-arbor.com/request.asp?JournalID =1\&ArticleID=3293\&Type $=2$. Acesso em: 30 abr. 2014.

GALVIN, M. F. A methodology for assessing and managing biodiversity in street tree populations: a case study. The Journal of Arboriculture, v. 25, n. 3, p. 124-128, maio 1999. Disponível em: http://joa.isa-arbor.com/request.asp?JournalID =1\&Arti- 
cleID $=2845 \&$ Type $=2$. Acesso em: 15 jan. 2014.

GOMES, Paulo Broering (org.). Manual para elaboração do plano municipal de arborização urbana. Curitiba: MEPMAU, 2012. (Série Cadernos Técnicos). Disponível em: http://www.meioambiente.mppr.mp.br/arquivos/File/planejamento_estrategico/6_Manual_PMARB.pdf. Acesso em: 4 nov. 2015.

JIM, C. The urban forestry programme in the heavily built-up milieu of Hong Kong. Cities, v. 17, p. 271-283, 2000.

LORENZI, H. Árvores brasileiras: manual de identificação e cultivo de plantas arbóreas nativas do Brasil. 2. ed. Nova Odessa: Instituto Plantarum, 2002. v. 2. 368 p.

LORENZI, H. Árvores brasileiras: manual de identificação e cultivo de plantas arbóreas nativas do Brasil. 5. ed. Nova Odessa: Instituto Plantarum, 2008. v. 1. 384 p.

LORENZI, H.; SOUZA, H. M.; TORRES, M. A. V.; BACHER, L. B. Árvores exóticas no Brasil: madeireiras, ornamentais e aromáticas. 2003. 368 p.

MARINGÁ (PR). Prefeitura. Câmara Municipal. Legislação: SAPL - Sistema de Apoio ao Processo Legislativo - Câmara Municipal de Maringá - Paraná. Disponível em: http://www.cmm.pr.gov.br/?inc=legislacao. Acesso em: 22 nov. 2015.

MARINGÁ (PR). Prefeitura. Diretoria de Tecnologia da Informação. Gerência de Processamento. Bairros de Maringá. Maringá: PMM, 2015. 1 mapa, color. Escala $1: 17.000$.

MARINGÁ (PR). Prefeitura. NRM U-20001: das calçadas: desenho, acessibilidade e mobilidade. Maringá: PMM, 2016a.

MARINGÁ (PR). Prefeitura. Secretaria de Serviços Públicos. Viveiro municipal de Maringá e gerência de arborização. Ofício protocolo nº 1008. Maringá: PMM, 2016b.

MASCARÓ, L. E. A. R.; MASCARÓ, J. L. Vegetação urbana. Porto Alegre: UFRGS, 2002. 242 p. 
MILANO, M. S. Avaliação quali-quantitativa e manejo da arborização urbana: exemplo de Maringá-PR. 1988. Tese (Doutorado em Engenharia Florestal) - Universidade Federal do Paraná, Curitiba, 1988. 120 p.

MILANO, M.; DALCIN, E. Arborização de vias públicas. Rio de Janeiro: Light, 2000. 226 p.

PARANÁ (Estado). Instituto Ambiental do Paraná. Reconhece como espécies exóticas invasoras no estado do Paraná as espécies relacionadas nos Anexos 1 (Plantas), 2 (Vertebrados) e 3 (Invertebrados) da presente Portaria $n^{0} 59$, de 25 de abril de 2015. Lex: Diário Oficial Executivo, n. 9446, p. 85, maio 2015.

REGO, R. L. O desenho urbano de Maringá e a ideia de cidade-jardim. Acta Scientiarum, v. 23, n. 6, p. 1569-1577, 2001. Disponível em: http://periodicos.uem.br/ ojs/index.php/ActaSciTechnol/article/view/2801/1853. Acesso em: 5 maio 2013.

SAMPAIO, A. C. F. Análise da arborização de vias públicas das principais zonas do plano piloto de Maringá-PR. 2006. Maringá. Dissertação (Mestrado em Geografia) - Universidade Estadual de Maringá, Maringá, 2006. 264 p.

SAMPAIO, A. C. F. O processo de degradação e o estado de conservação da flora nos fragmentos florestais da área rural do Município de Maringá, Paraná. Tese (Doutorado em Geografia) - Universidade Estadual de Maringá, Maringá, 2013. $117 \mathrm{p}$.

SHAFER, E. L.; MOELLER, G. H. Urban Forestry: its scope and complexity. Journal of Arboriculture, v. 5, n. 9, p. 206-209, sep. 1979. Disponível em: http://joa.isa-arbor.com/request.asp?JournalID $=1 \&$ ArticleID $=1600 \&$ Type $=2$. Acesso em: $15 \mathrm{dez}$. 2014.

Recebido em: 25/01/2018

Aceito em: 26/09/2018 